\title{
A foreword from the Editor-in-Chief
}

\author{
Aaron S. Dumont \\ Department of Neurological Surgery, Tulane University, New Orleans, LA 70112, USA.
}

Correspondence to: Dr. Aaron S. Dumont, Department of Neurological Surgery, Tulane University, 131 South Robertson Street, Suite 1300, New Orleans, LA 70112, USA. E-mail: adumont2@tulane.edu

How to cite this article: Dumont AS. A foreword from the Editor-in-Chief. Vessel Plus 2017;1:1-2.

Article history: Received: 22-01-2017 Accepted: 23-01-2017 Published: 31-03-2017

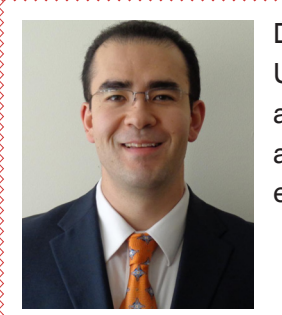

Dr. Dumont serves as the Charles B. Wilson Professor and Chair of the Department of Neurosurgery at Tulane University School of Medicine. He is a board-certified neurosurgeon who completed his residency program training at the University of Virginia as well as a fellowship in cerebrovascular, skull base and endovascular neurosurgery at the University of Virginia. He has active neurosurgical research interests and has published and presented extensively with more than 200 publications and more than 175 national and international presentations.

Welcome to the inaugural issue of Vessel Plus. This recently launched journal from OAE Publishing Inc., is an international, peer-reviewed, open access journal dedicated to publishing articles focused on vascular physiology, biology and disease.

I would like to thank and extend my gratitude to my co-editors, editorial board members, reviewers, members of OAE Publishing Inc., especially Sylvia Wang, as well as the contributing authors for creating this first issue.

Vessel Plus publishes articles related to all diseases caused by pathological change of blood vessels, including stroke, hypertension, aneurysm and coronary artery and peripheral vascular diseases and thrombosis. This journal focuses on the latest clinical and basic research on the prevention, treatment and prognosis of disease of the blood vessels including those of the arterial and venous circulation as well as the microcirculation.

In this issue, readers will find a diverse group of manuscripts. Sobenin et al. ${ }^{[1]}$ have provided new insight into the nature of low density lipoprotein modifications in diabetic compared to non-diabetic patients. Schiavone et all.[1] have compared the mechanical performance of metallic compared to bioresorbable polymeric stents during the process of crimping and deployment using finite element modelling. Additionally, Dong et al. ${ }^{[3]}$ have reviewed the potential therapeutic role of a mimetic peptide of the ubiquitin-interacting motif of epsin, through regulation of VEGFR2 signaling, in brain tumors.

This is indeed an exciting time for Vessel Plus. Our journal will allow rapid publication of manuscripts after rigorous peer review, free of charge to the authors with open access, facilitating widespread dissemination and impact on the field. Future special issues may include a thematic focus on original research as

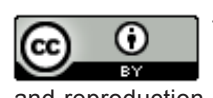
Lice This is an open access article licensed under the terms of Creative Commons Attribution 4.0 International License (https://creativecommons.org/licenses/by/4.0/), which permits unrestricted use, distribution, and reproduction in any medium, as long as the original author is credited and the new creations are licensed under the identical terms.

For reprints contact: service@oaepublish.com

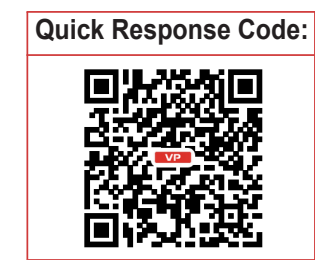


well as reviews and editorials by luminaries in the field. We look forward to helping advance the field of vascular research by providing a premier medium for publication.

Financial support and sponsorship

None.

\section{Conflicts of interest}

There are no conflicts of interest.

\section{Patient consent}

Not applicable.

\section{Ethics approval}

Not applicable.

\section{REFERENCES}

1. Sobenin IA, Galitsyna EV, Grechko AV, Orekhov AN. Small dense and desialylated low density lipoprotein in diabetic patients. Vessel Plus 2017 Jan 19. [Online First]

2. Schiavone A, Qiu TY, Zhao LG. Crimping and deployment of metallic and polymeric stents -- finite element modelling. Vessel Plus 2017 Jan 19. [Online First]

3. Dong Y, Wu H, Dong J, Song K, Rahman HA, Towner R, Chen H. Mimetic peptide of ubiquitin-interacting motif of epsin as a cancer therapeutic-perspective in brain tumor therapy through regulating VEGFR2 signaling. Vessel Plus 2016 Dec 27. [Online First] 